\title{
LISTERIA MENINGITIS IN A THREE YEAR OLD IMMUNOCOMPETENT CHILD: A CASE REPORT FROM A TERTIARY CARE HOSPITAL IN NEPAL
}

\author{
Nayak $N,{ }^{1}$ Baral $N,{ }^{1}$ Bahadur $N,{ }^{2}$ Gokhale $S,{ }^{1}$ Gowda $S,{ }^{1}$ Hamal $D,{ }^{1}$ Bhatta $D R,{ }^{1}$ Rao KS
}

${ }^{1}$ Department of Microbiology, ${ }^{2}$ Department of Paediatrics, Manipal College of Medical Sciences, Pokhara, Nepal

\begin{abstract}
Listeria. monocytogenes may cause meningitis, meningoencephalitis, brain abscess, pyogenic arthritis, osteomyelitis, and liver abscesses in the pediatric age group. Listeria meningitis, though common in infants, is extremely infrequent in immunocompetent children. The course of meningoencephalitis by Listeria is often severe and even fatal, especially in those having an underlying predisposing condition. We hereby report a case of meningitis due to $L$. monocytogenes in a previously healthy three year old female child. The case is reported for its rarity and fatal outcome in an immunocompetent child. A three year old female child was referred to Manipal Teaching Hospital, a tertiary care hospital in western Nepal after three days of treatment with IV ceftriaxone for fever, excessive sleepiness and cough. The child had developed all features of meningitis and was kept on IV ceftriaxone and vancomycin. Culture of her CSF and blood grew L. monocytogenes. However, before the culture and sensitivity report for switch over of the antibiotics could be available, the child died in spite of supportive management for seizures, hypoxia and hypotension. This was an uncommon pathogen to cause meningitis considering the age of the child and her immune status. Thus there should always be a high index of suspicion among the clinicians and microbiologists for such rare pathogens which might be intrinsically resistant to many empirically administered antibiotics.
\end{abstract}

\section{KEYWORDS}

Listeria monocytogenes, meningitis, immunocompetent child, pediatric patient

\section{CORRESPONDING AUTHOR}

Prof. Nirajan Nayak,

Department of Microbiology,

Manipal College of Medical Sciences,

Pokhara, Nepal

Email: niruni2000@yahoo.com 


\section{INTRODUCTION}

Listeria are gram positive short rods, often pleomorphic and motile at room temperature. ${ }^{1}$ Of all the members of Listeria, Listeria monocytogenes happens to be a human pathogen. This organism is found in the soil and water, wild animals, and livestock, and usually causes human infection through contaminated food. ${ }^{2} L$. infections are commonly seen in immunocompromised patients, pregnant women, and infants; but are extremely unusual in healthy children. ${ }^{2-4}$ It can cause invasive and disseminated disease including central nervous system infections, endocarditis, and sepsis, especially in patients with organ transplants, with malignancies and on immunosuppressive therapy. ${ }^{5,6}$ An infection during pregnancy can cause miscarriage, and premature birth, as well as amnionitis, disseminated abscess accompanied by sepsis, late-onset meningitis and pneumonia. ${ }^{7}$

Meningitis due to Listeria, though commonly encountered during the neonatal period, is not uncommon among immunocompromised individuals of other age groups. However, there are scanty reports of listeriosis in immunocompetent subjects, especially in children. ${ }^{8}$ In view of the above, we report a case of meningitis due to $L$. monocytogenes in a three year old immunocompetent child with normal developmental milestones and without any underlying predisposition.

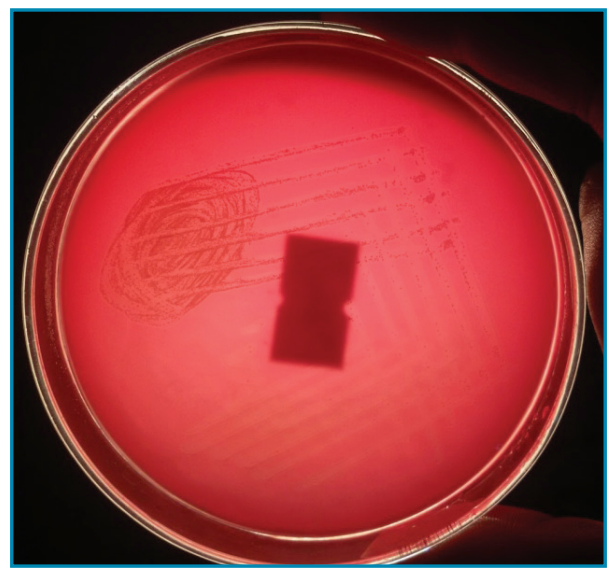

Fig. 1: 5\% Sheep Blood Agar showing beta haemolytic colonies.

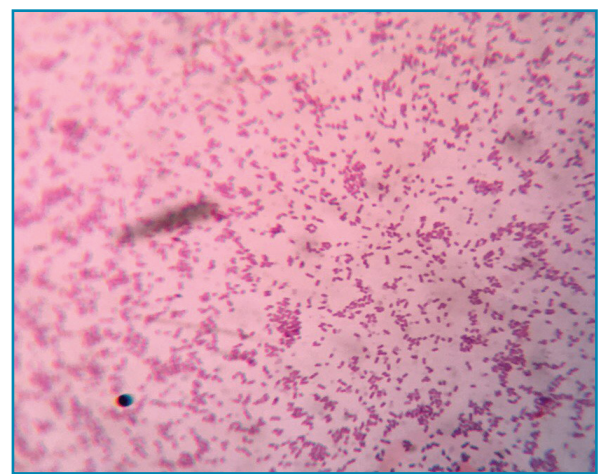

Fig. 2: Gram stained preparation showing gram positive pleomorphic coccobacilli.

\section{CASE REPORT}

A 3-year-young female child, referred to Manipal Teaching Hospital, Pokhara, Nepal presented with complaints of fever since 5 days, occasional cough since four days, excessive drowsiness since three days and diminished response since one day. Upon enquiry from the mother, it was noted that fever was

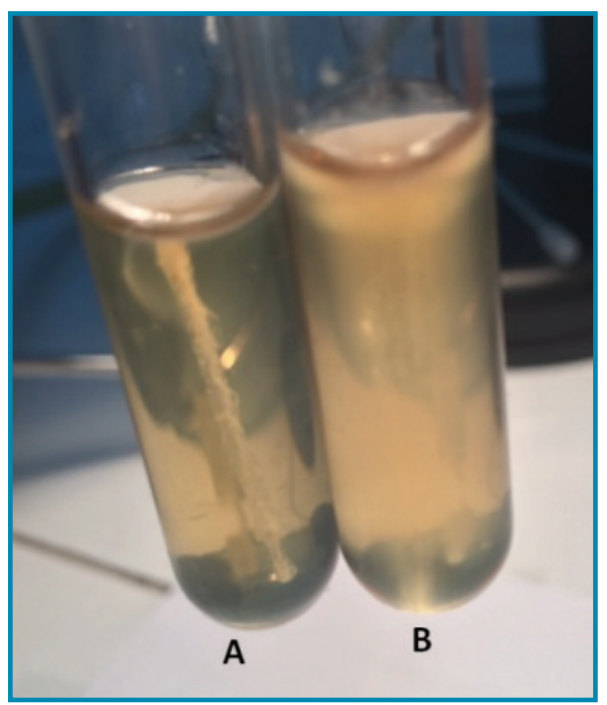

Fig. 3: Organism showing motility in SIMincubated at $25^{\circ} \mathrm{C}$, (B ) while there was absence of motility on incubation at $37^{\circ} \mathrm{C}(\mathrm{A})$.

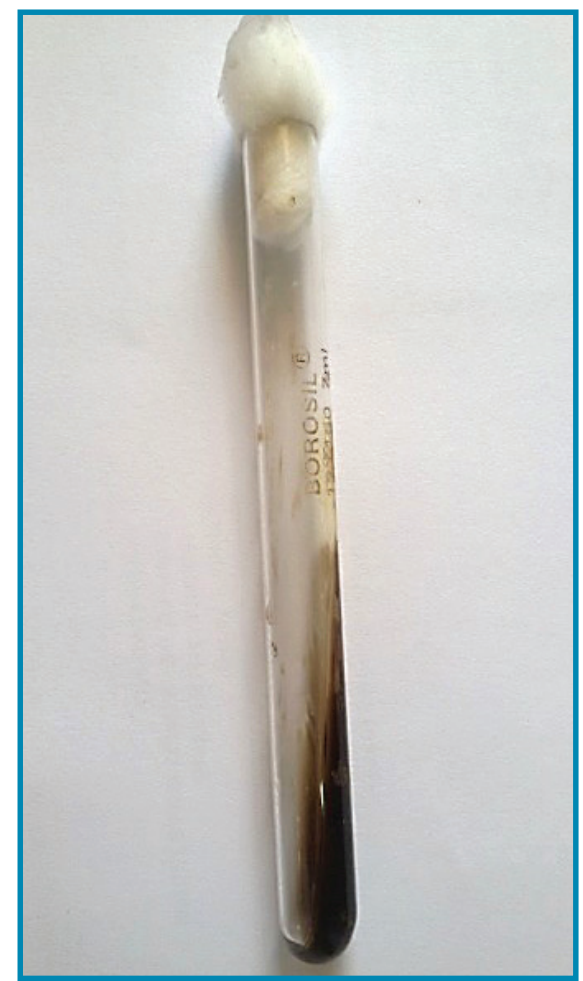

Fig. 4: Bile esculin agar showing hydrolysis of esculin by the organism .

intermittent in nature reaching $100^{\circ} \mathrm{F}$ accompanied by chills and rigor with sweating. The child had occasional cough lasting $<1 \mathrm{sec}, 2-3$ bouts/episode, 10 12 episodes/day with occasional projectile vomiting 
containing food particles. The mother also provided history regarding the child's excessive sleepiness, decreased feeding and decreased responsiveness since few days preceding her present illness. The child was vaccinated as per schedule. There were no rashes on the body, no abnormal body movement or bluish discolouration. The patient was treated at other medical facility with antipyretics, cough syrup and intravenous ceftriaxone. In spite of this treatment for 3 days, her condition deteriorated and she was referred to the Manipal Teaching Hospital (MTH), a tertiary care teaching hospital in western Nepal.

On examination, the child had an average built, with definitive signs and symptoms of meningitis, including neck rigidity and features of raised intracranial tension. The child developed seizures on the day of admission within an hour and her blood pressure dropped to 66/ $27 \mathrm{~mm} \mathrm{Hg}$ within the next 8 hours. Thus she was managed with anticonvulsants and vasoppressure drugs in addition to continuance of empirical ceftriaxone $650 \mathrm{mg}$ IV BD $(100 \mathrm{mg} / \mathrm{kg}$ body weight per day in two divided doses; weight of the baby being $13 \mathrm{~kg}$ ) and Inj vancomycin $190 \mathrm{mg}$ (50-60 mg/kg body weight per day in divided doses) in $50 \mathrm{ml}$ normal saline over one hour qid. The CSF was turbid and showed $18 \mathrm{WBC} /$ cubic millimetre; predominantly lymphocytes. Protein content was $182 \mathrm{mg} / \mathrm{dl}$, and sugar $5 \mathrm{mg} / \mathrm{dl}$. CT scan of brain was normal. The $\mathrm{CBC}$ picture depicted a total WBC of 13900/mm, ${ }^{3}$ neutrophil 57\%, lymphocytes $43 \%$, Hb $10.3 \%$, and platelet count $1,00,000 / \mathrm{mm}^{3}$

Gram staining of the CSF showed mononuclear cells but no bacteria could be found. The CSF was inoculated onto sheep Blood Agar (BA), Chocolate Agar (CA), and MacConkey Agar (MAC). After 24 hours of incubation, the BA plate showed growth of small, round, smooth, translucent beta haemolytic colonies (Fig.1). CA also revealed growth of tiny smooth glistening colonies. No growth however, was detected on the MCA plate. Blood culture showed turbidity after 72 hours of incubation. Subculture onto BA showed smooth round beta haemolytic colonies similar to those from CSF. Gram staining from colonies showed gram positive, short, nonsporing bacilli with diptheroid like arrangement (Fig. 2).

Tumbling motility was demonstrated by a hanging drop preparation from the growth in nutrient broth and sulphide indole motility (SIM) agar incubated at $25^{\circ} \mathrm{C}$ showed that the organism was motile at room temperature. However, it did not show motility when tested from the culture in nutrient broth and SIM incubated at $37^{\circ} \mathrm{C}$ (Fig. 3). The organism was capable of growing at $4^{\circ} \mathrm{C}$. It was catalase positive, oxidase negative, did not produce $\mathrm{H}_{2} \mathrm{~S}$ and hydrolysed esculin (Fig. 4). The isolate was, thus, identified as $L$. monocytogenes based on the above mentioned characteristics. ${ }^{9}$ The organism was sensitive to penicillin, chloramphenicol, erythromycin and polymixin B, but resistant to ceftriaxone and ampicillin.

Despite empirical antibiotics and supportive management for seizures, hypoxia and hypotension the patient died on day three of her admission. The culture and sensitivity report for switch over of antibiotic therapy was not available ante mortem. Autopsy was not performed as the parents did not consent for it.

\section{DISCUSSION}

L. monocytogenes usually presents as bacteraemia or meningitis or both. The predisposing factors include pregnancy, diabetes mellitus, malignancy, collagen disorders and immunosuppression. ${ }^{10}$ In cases of early onset neonatal Listeriosis, the infant is infected in utero presumably by transplacental infection from the bacteraemic mother. Though Listeriosis is common in neonates, it is rare in immunocompetent children. ${ }^{11}$

Clinical progress of meningoencephalitis caused by Listeria is rapid and the disease is invariably associated with high mortality rate. ${ }^{4,12}$ The present case was a three year old healthy immunocompetent child and thus was thought to be an unlikely candidate for Listeriosis. Therefore, the child was kept on empiric ceftriaxone and vancomycin before being referred to MTH and was continued with the same regimen awaiting the culture and sensitivity report. The child expired before the culture and sensitivity report from CSF or blood was available.

The common etiological agents ofmeningitisin this age group are Haemophilus influenzae and Streptococcus pneumoniae. Therefore, many institutions advocate empiric treatment of suspected bacterial meningitis with $3^{\text {rd }}$ generation cephalosporins. ${ }^{13}$ Alarmingly, Listeria is intrinsically resistant to cephalosporins.9,14 Listeria is not known to be resistant to vancomycin hence in vitro susceptibility test against vancomycin was not performed. Recommended treatment of Listeria meningitis includes a combination therapy of ampicillin (25- $100 \mathrm{mg} / \mathrm{kg}$ body weight 4 hourly) and gentamicin $(1-1.7 \mathrm{mg} / \mathrm{kg}$ body weight 8 hourly for synergy) for at least 2-3 weeks. $^{12}$ Although case reports documented partial success with vancomycin, there have been evidences of clinical failure with this agent. ${ }^{12}$ Thus empirical treatment with ceftriaxone and vancomycin in such cases could prove catastrophic. ${ }^{15}$

Success rates in treating Listeria meningitis are reported to be high with the use of ampicillin or penicillin combined with aminoglycosides like amikacin or gentamicin, while penicillin resistant or penicillin allergic cases were effectively treated with trimethoprim-sulfamethoxazole., ${ }^{2,16}$ The isolate in our case was sensitive to penicillin, but resistant to ceftriaxone and ampicillin. Though ceftriaxone resistance in Listeria is not uncommon, ${ }^{9,14}$ ampicillin resistance and penicillin sensitive strains have been reported earlier. Safdar and Armstrong documented clinical isolates of $L$. monocytogenes resistant in vitro to peniciilin and/or ampicillin. ${ }^{17}$ In accordance with the above, it was proposed that resistance in some strains of L. monocytogenes to ampicillin was not because of beta-lactamase activity or altered 
penicillin binding proteins (PBPs), but could be due to acquisition of transposon carrying genetic elements in vivo from other bacteria. ${ }^{17,18}$ Since transposons were frequently transferred between representatives of various Listeria species and also from other gram positive bacteria like Enterococcus, it is easy to envisage an in vivo situation in which such molecules might induce resistance to ampicillin. ${ }^{18}$

In clinical specimens, the organism can be observed to be gram variable, and due to its morphological resemblance with many Diphtheroids, $L$. monocytogenes may often be regarded as a contaminant. CSF direct smear showing lymphocytic pleocytosis and CSF analyses commensurate with meningitis and/ or meningoencephalitis,, 111 accompanied by isolation of a diphtheroid like organism from CSF should never be disregarded. One should always have a high index of suspicion while encountering such rare pathogens and should always be vigilant of the possibility that the pathogen could be Listeria monocytogenes, ${ }^{19,20}$
Discordant penicillin and ampicillin sensitivity/ resistance should be confirmed by other advanced investigations.

In conclusion, this case report highlights the need for awareness among the physicians and microbiologists about uncommon pathogens and their uncommon antibiogram. The gram positive bacillus from CSF and blood culture may not necessarily be a contaminant. It should be properly identified. The empirical antibiotic treatment needs review if the clinical response is inadequate.

\section{ACKNOWLEDGEMENT}

The authors acknowledge the parents of the child to give their consent for publishing this work, in spite of the fact that the child's life could not be saved in spite of all our efforts.

\section{REFERENCES}

1. Murray EGD, Webb RA, Swann MBR. A disease of rabbits characterized by a large mononuclear leucocytosis caused by a hitherto undescribed bacillus, Bacterium monocytogenes. J Pathol Bacteriol 1926; 29: 407-39.

2. Lee JE, Cho WK, Nam CH, Jung MH, Kang JH, Suh BK. A case of meningoencephalitis caused by Listeria monocytogenes in a healthy child. Korean J Pediatr 2010; 53: 653-6.

3. Lobotkova D, Dicka E, Rolny V, Stankovic I, Ciznar P. Systemic Listeria monocytogenes infection in a 2-yearold immunocompetent child. Infection 2014; 42: 10559.

4. Ulloa-Gutierrez R, Avila-Agüero ML, Huertas E. Fulminant Listeria monocytogenes meningitis complicated with acute hydrocephalus in healthy children beyond the newborn period. Pediatr Emerg Care 2004; 20: 233-7.

5. Peer MA, Nasir RA, Kakru DK, Fomda BA, Wani MA, Haqeem QN. Listeria monocytogenes meningoencphalitis in an immunocompromised previously healthy 20 month old female child. Indian J Med Microbiol 2010; 28: 169-71.

6. Pagliano P, Ascione T, Boccia G, De Caro F, Esposito S. Listeria monocytogenes meningitis: epidemiological, clinical and therapeutic findings. Infez Med 2016; 24: 105-11.

7. Suh JT, Lee JD. Neonatal listeria and septicaemia. Korean J Clin Pathol 1982; 2: 81-6.

8. Kessier SL, Dajani AS. Listeria meningitis in infants and children. Pedatr Infect Dis J 1990; 9: 61-3.

9. Smith G. Erysipelothrix and Listeria. In: Wilson G, Miles A, Parker MT, editors. Topley and Wilson's Principles of bacteriology, virology and immunity. Vol II. $7^{\text {th }}$ Ed. London: Edward Arnold; 1983 and 1984. P.50-59.

10. Gupta V, Gautam V, Mehta N,Kumari I, Joshi RM. Listeriosis in second trimester of pregnancy: Case report from India. Jpn J Infect Dis 2003, 56; 60-1.
11. Ben-Shimol S, Einhorn M, Greenberg D. Listeria meningitis and ventriculitis in an immunocompetent child: case report and literature review. Infection 2012; 40: 207-11

12. Hohmann EL, Portnoy DA. Listeria monocytogenes infections. In: Longo DL et al, ed. Harrison's Principle of Internal Medicine. Vol I. $18^{\text {th }}$ ed. New York; 2012. p, 1194-6

13. Roos KL, Tyler KL. Meningitis, Encephalitis, Brain abscess and Empyema. In: Longo DL et al, ed. Harrison's Principle of Internal Medicine. Vol II. $18^{\text {th }}$ ed. New York; 2012. p, 3410-34

14. Lorber B. Listeriosis. Clin Infect Dis 1997; 24: 1-11.

15. Economou M, Karyda S, Kansouzidou A, Kavaliotis J. Listeria meningitis in children: report of two cases. Infection 2000; 28: 121-3.

16. Polat M, Kara SS, Tapisiz A, Derinoz O, Caglar K, Tezer H. Successful treatment of refractory listeria meningitis and bacteremia with trimethoprimsulfamethoxazole in an immunocompetent child. The Turkish J Paed 2016; 58: 220-2.

17. Safdar A, Armstrong D. Antimicrobial activities against 84 Listeria monocytogenes isolates from patients with systemic Listeriosis at a comprehensive cancer center (1955-1997). J Clin Microbiol 2003; 41: 483-5

18. Poros-Gluchowska J,Kloszewska M,Markiewicz Z. Ampicillin resistance in Listeria monocytogenes acquired as aresult of transposon mutagenesis. Acta Microbiologica Polonica 2003; 52: 131-42

19. Rai SK,Ono K, Yanagida JI, Kurokawa M, Rai CK. Study of drinking water contamination in mountain region in Nepal. Nepal Med Coll J 2009; 11: 281-3.

20. Rai SK, Ono K, Yanagida JI, Ishiyama S, Kurokawa M, Rai CK. A large scale study of bacterial contamination of drinking water and its public health impact in Nepal. Nepal Med Coll J 2012 14: 234-40. 